\title{
Possibility of implementing a cluster based on the territorial public self-government that includes sports, retailers and consumer services
}

\author{
Arkadii Simdiankin ${ }^{1}$, Egor Khludnev ${ }^{1, *}$, Pavel Probin ${ }^{1}$, and Alexey Yamalutdinov ${ }^{2}$ \\ ${ }^{1}$ Russian State University of Physical Culture, Sport, Youth and Tourism, Sirenevy Blvd. 4, Moscow, 105122, Russia \\ ${ }^{2}$ Russian Foreign Trade Academy, 6A, Vorobiovskoe high-road, Moscow, 119285, Russia
}

\begin{abstract}
The economic crisis has had a negative impact on the clustering processes. Nevertheless, in the current conditions there is a prospect of changing the very ideology of cluster models. It is very likely that the high impact of the volatility factor in the business environment will determine a qualitatively new format for the implementation of cluster initiatives. In most cases, the population of a particular territory is not directly involved in the process of creating a cluster but is considered as a labour force capable of achieving the goals of clustering. However, it is impossible to say that cluster projects cannot be initiated on the principle of "bottom-up development" where the population performs are not only the functions of "personnel" but also determines the feasibility of forming a project. This ensures open an equal access to the resources of absolutely all cluster participants and the population acts as an initiator, coordinator, investor and source of labour resources. In this regard, we think that it is appropriate and possible to consider the prospect of creating cluster (and similar ones) projects by the example of territorial public self-governments.
\end{abstract}

\section{Introduction}

As noted in the literature, in many developed countries the sustainability of economic development is directly related to small and medium-sized businesses (SME). Our country is also aware of the importance of this sector of the economy. In order to develop it, a set of measures is being carried out aimed at improving the conditions for small and medium-sized businesses and promoting them [2].

These measures should lead to an increase in the number of SME employees from 19.2 to 25 million people in the period from 2018 to 2024. Besides the fraction of small and medium-sized businesses in the country's GDP should rise from 22.3 to $32.5 \%$ [3]. However, in 2019 the number of SME decreased by 2\% (from $6,041,195$ to $5,916,906)$ as well as the number of employees decreased by $3.5 \%$ (from $15,873,589$ to $15,321,788$ ) [4]. During 2020 the situation only worsened because of COVID-19 pandemic. However, it does not cancel other factors that cause the economic vulnerability of SME such as their inability to compete effectively with representatives of large businesses [5]. The above circumstances clearly indicate the need to find new ways to create favorable conditions for the development of small and medium-sized businesses in our country.

\section{Review of literature}

In view of this it is advisable to pay attention to the fact that the economic stability of SME is markedly increasing within clusters where logistics, personnel and other opportunities are becoming wider because of it's realized on the basis of common efforts [6].

The practical effectiveness of the cluster approach as a factor in the development of SME is repeatedly mentioned in the scientific literature where the positive experience of implementing cluster projects in different regions of the Russian Federation describes $[7,8]$. For example, in

* Corresponding author: hei14@mail.ru 
the Tambov region the trade turnover of small and medium-sized enterprises reached over 160 billion rubles in 2013 . This is equivalent to $43.8 \%$ of the total turnover of all organizations operating in this region [9].

This suggests the feasibility of conducting a policy on the territory of our country aimed at involving small and medium-sized businesses in the activities of clusters. As one of the possible vectors of such a policy the authors see the formation of clusters around territorial public selfgovernments (TPSG) - self-organizations of citizens at their place of residence for the independent implementation of their own initiatives on issues of local significance. The boundaries of the territory are established by the representative body of the municipal formation based on the suggestion of the population and can cover both a small territory (for example, the entrance of an apartment building) and a residential community or a locality that does not have the status of a municipal formation. Citizens living in the relevant territory form TPSG' management bodies that represent their interests interacting with local self-government authorities and can carry out economic activities aimed at social and household needs of residents.

Despite the fact that the abovementioned economic activities can be carried out not only on a donation basis of the citizens themselves but also on the taxpayers dime the financial resources of the TPSG' management bodies are not enough as a rule.

\section{Methods}

It seems the establishment of symbiotic relations between TPSG and SME entities that conduct economic activities in the territory within the boundaries of which territorial public self-government is carried out can reduce the acuteness of this problem. We see the direction of their mutually beneficial cooperation in the implementation by the TPSG' management bodies of a common bonus loyalty scheme. In this condition SME when purchasing goods (works, services) by program participants (i.e., citizens) would accrue bonus points (de jure - the obligation to provide a discount) and would make deductions to the program organizer in the amount of this discount. For example, a citizen purchasing a product in a grocery connected to the loyalty program can spend bonus points from any other partner of the program - a sports club, a barber shop, a pharmacy, etc.

The tasks of the TPSG' management bodies will include the reimbursement of the discounts provided to the partners of the loyalty program with the deduction of their agency fee that can be used to achieve the goals for which the TPSG was created. Thus, citizens will understand that by buying goods or ordering works and services from the program partners they contribute to the improvement of the territory where they live.

Of course, this system can be effective only if the TPSG authorities make efforts to ensure that citizens know what the economic entities have joined the loyalty program. Therefore, it is advisable to post information about the program's partners on the Internet. Thus, people will be able to easily find sellers and performers which can be not only organizations but also individual entrepreneurs and self-employed persons [10].

The main problem in the implementation of the described concept is likely to be the technical side of its implementation. But it can be solved by creating maybe with the support of the state - a common Internet portal where TPSG' management bodies could register as organizers of loyalty programs and SMEs and citizens could connect to the programs, they are interested in. It is worth considering the possibility of an automated payment system between the organizers and partners of the loyalty program as part of such an online platform. It also makes sense to develop an appropriate mobile app.

Local self-government bodies can also make a significant contribution to the implementation of the idea under consideration by help to inform the population about TPSG that implement the described loyalty programs as well as encouraging TPSG to independently attract financial resources.

From this perspective it is interesting that the experience of the Perm urban district where a system of competitions for socially significant projects is implemented in order to increase the activity of the population in solving local issues. To participate in the TPSG competition it is necessary not only to develop a project but also to independently attract at least $30 \%$ of the resources needed for its implementation. The winners of the competition receive the corresponding grants [11]. It seems that such a system makes it possible to use the local budget more effectively not only because the solution of local issues is partially carried out at the expense of private capital. But also because of its involvement the population in this process since often only the residents themselves know exactly how to solve certain current issues for them [12].

Let us pay attention to a number of features inherent in clusters formed on the basis of TPSG. First, this type of cluster can be called complex since they can include organizations of a wide variety of economic sectors. The main thing is their territorial location and the opportunity to be useful for the local community. It makes them possibility to carry out activities in a more favorable business environment than enterprises that cannot become part of an industry cluster. For example, this applies to sports clubs in the place of residence. 
Second, the cores of the clusters under consideration (i.e., TPSG) have certain public functions. In particular, they have the right to submit to local self-government bodies mandatory draft municipal legal acts for consideration. This means that the TPSG can effectively act as a mediator in the dialogue between the cluster participants and local authorities including the issues related to improving the investment climate in the territory of the municipality.

Third, TPSG is created and functions thanks to the "bottom-up development" initiative that is in a natural way. It is very important taking into account the fact that effective clusters (as world experience shows) very rarely arise artificially [13].

Fourth, within a municipality there can be as many TPSG as the population needs since the legislation does not limit their maximum number. Since the municipalities are formed throughout the entire territory of our country, there is a possibility of formation of such a number of clusters around territorial public selfgovernments that the economy needs at both the mesoand macrolevels.

To analyze the possibility of clustering the authors propose to apply some operations of set theory in particular the intersection operation (denoted as $A \cap B$ and is a set of elements contained in both set $\mathrm{A}$ and set B). At the same time, both A and B is a set of elements that describe the relationship of the business cluster groups to the sources of funding, potential involvement and interest to be in the cluster. This approach allows us to identify the "points of contact" of the interests of various groups of the cluster being formed as well as to determine (with a high degree of confidence) the possibility or impossibility of creating a cluster at this stage and with these participants.

\section{Results}

We consider the "motivating" features of economically active organizations that encourage them to the clustering process. Based on the above-mentioned analysis of literature sources as well as actual data [4], [13-18] the authors identified the "interests" of TPSG and business clusters (BC) with industry (Table 1), sources of financing (Table 2) and the potential involvement of various groups potentially interested in the work of the cluster (Table $3)$.

Let's consider TPSG and BC as two sets and find their intersection (Table 1):

$\operatorname{TPSG}_{1}(0,1 ; 0,1 ; 0,3 ; 0,1 ; 0,3 ; 0 ; 0,1) \cap$

$$
B C_{1}(0,15 ; 0,2 ; 0,1 ; 0,1 ; 0,3 ; 0,1 ; 0,05)
$$

The result of the intersection of these two sets is the following set:

$$
\operatorname{SI}_{1}(0,1 ; 0,1 ; 0,1 ; 0,1 ; 0,3 ; 0 ; 0,05)
$$

and its maximum value is $\max \left(\mathrm{SI}_{1}\right)=0,3$.

Table 1. Intersection of sets TPSG and BC within an industry.

\begin{tabular}{|l|r|r|r|}
\hline & TPSG & \multicolumn{1}{c|}{ BC } & Intersection \\
\hline Industrial production & 0,1 & \multicolumn{1}{c|}{0,15} & 0,1 \\
\hline Food and pharmaceutical industries & 0,1 & 0,2 & 0,1 \\
\hline Service & 0,3 & 0,1 & 0,1 \\
\hline Farm sector & 0,1 & 0,1 & 0,1 \\
\hline Distributive industries & 0,3 & 0,3 & 0,3 \\
\hline Building activity & 0 & 0,1 & 0 \\
\hline Residential and public landscaping & 0,1 & 0,05 & 0,05 \\
\hline \multicolumn{1}{|c|}{ Sum } & \multicolumn{1}{|c|}{1} & 1 & 0,75 \\
\hline
\end{tabular}

Based on the analysis of the SI1-set it can be concluded that cooperation within the cluster between business and territorial public self-government is possible in the field of wholesale and retail trade. At the same time, the small value of maximum indicates the limited maneuver of the business represented in this field in the development of the cluster. First of all, this restriction is due to the small financial resources of this kind of business. Moreover, it is difficult to call such business as a start-up and therefore no one should expect an "explosive" growth in its activity as well as the same

"explosive" growth in attracting funds from potential investors and the growth in the cluster's revenue. This situation is likely to be accompanied by a rather slow attraction of budget funds from the TPSG which will be invested in the cluster. Of 
course, business is interested in additional financing and will be willing to consume additional budget funds attracted by the TPSG. This approach will determine the very existence of the cluster on the principle of "there is money - there is a cluster, there is no money - there is no cluster" since budget financing will be perceived by the business exclusively as an additional source of income. This interpretation will be a barrier to the development of the cluster.

Table 2. Intersection of sets TPSG and BC within the sources of financing.

\begin{tabular}{|l|l|l|l|}
\hline & TPSG & BC & Intersection \\
\hline $\begin{array}{l}\text { State aid } \\
\text { (programs, funds) }\end{array}$ & 0,6 & 0,3 & 0,3 \\
\hline Foreign investors & 0 & 0,1 & 0 \\
\hline Venture funds & 0 & 0,1 & 0 \\
\hline Local Russian investors & 0,1 & 0,2 & 0,1 \\
\hline Business angel investors & 0 & 0,1 & 0 \\
\hline Banks Sum & 0,3 & 0,2 & 0,2 \\
\hline \multicolumn{1}{|c|}{ Sum } & 1 & 1 & \multicolumn{2}{|c|}{0,6} \\
\hline
\end{tabular}

by budget funds with a focus on financing TPSG but not business.

Let's perform the similar actions with the data in Table 2.

$$
\begin{array}{r}
\operatorname{TPSG}_{2}(0,6 ; 0 ; 0 ; 0,1 ; 0 ; 0,3) \cap \\
B_{2}(0,3 ; 0,1 ; 0,1 ; 0,2 ; 0,1 ; 0,2)
\end{array}
$$

The result of the intersection of these two sets is the following set:

$$
\operatorname{SI}_{2}(0,3 ; 0 ; 0 ; 0,1 ; 0 ; 0,2)
$$

and its maximum value is $\max \left(\mathrm{SI}_{2}\right)=0,3$.

Thus, financial support for the possible formation of a cluster based on the interaction of TPSG-BC is again supported
In $\mathrm{SI}_{2}$-set the second largest member of this set is "banks" $(0,2)$. Banks' position will significantly affect the financing of the cluster at the local level. However, the member of the TPSG2-set for banks is larger than the one for business - it indicates a higher attractiveness in the financing of TPSG by banks than for business. On the other hand, such financing can also be carried out not at the initiative of banks but by order of "governmental authorities" - as financing for a group that developed the local community.

Table 3. Intersection of sets TPSG and BC of various groups potentially interested in the work of cluster.

\begin{tabular}{|l|r|r|r|}
\hline & \multicolumn{1}{|c|}{ TPSG } & \multicolumn{1}{c|}{ BC } & Intersection \\
\hline Industrial plants, raw material processing, service, farm sector & 0,15 & 0,3 & 0,15 \\
\hline Small and medium-size enterprises & 0,3 & 0,4 & 0,3 \\
\hline Individual entrepreneurs & 0,3 & 0,1 & 0,1 \\
\hline Self-employed persons & 0,15 & 0,1 & 0,1 \\
\hline Retirees & 0,05 & 0,05 & 0,05 \\
\hline Unemployed population Sum & 0,05 & 0,05 & 0,05 \\
\hline \multicolumn{1}{|c|}{ Sum } & 1 & 1 & 0,75 \\
\hline
\end{tabular}

$\operatorname{TPSG}_{3}(0,15 ; 0,3 ; 0,3 ; 0,15 ; 0,05 ; 0,05) \cap$

Let's perform the similar actions with $B C_{3}(0,3 ; 0,4 ; 0,1 ; 0,1 ; 0,05 ; 0,05)$ the data in Table 3. 
The result of the intersection of these two sets is the following set:

$$
\operatorname{SI}_{3}(0,15 ; 0,3 ; 0,1 ; 0,1 ; 0,05 ; 0,05)
$$

and its maximum value is $\max \left(\mathrm{SI}_{3}\right)=0,3$.

It is clearly seen that small and mediumsized businesses (as a rule specializing in wholesale and retail trade) are most interested in clustering. At the same time, this type of business is almost equally represented by both TPSG (0.3) and business structures (0.4).

\section{Conclusions}

Considering the total values of all intersections we can come to the following conclusion: the similar "desire" of TPSG and $\mathrm{BC}$ to enter the cluster within the industry and the involvement of various groups potentially interested in the work of the cluster is not supported at the proper level by potential investors. This indicates some concern about the "sources of funding" in the success of this type of cluster. The proposed approach to assessing the formation of a cluster based on the compilation of sets that include various aspects of the cluster, sources of funding, groups of people interested in its work and direct participation in it as well as sectors of the national economy allows us to comprehensively consider the impact of the current situation on the clustering process and identify the main obstacles on this path.

\section{References}

1. N. Goridko., R. Nizhegorodtsev The econ. of the reg. 14, 30 (2018)

2. YU. Baldina Bull. of the Udm. Uni. Econ. and Law ser. 26, 7 (2016)

3. Presidium of the Presidential Council for Strategic Development and National Projects Protocol No. 16 Passport of the national project "Small and Mediumsized Enterprises and Support for Individual Entrepreneurial Initiatives» (2018)

4. Official website of the Federal Tax Service of Russia Unified Register of
Small and Medium-sized Businesses Retrieved from: https://ofd.nalog.ru

5. M. Vyshegorodtsev Mod. competit. 5(17), 53 (2009)

6. G. Zelenkov Innov. and invest. 12, 212 (2017)

7. N. Solodilova, R. Malikov, K. Grishin. Econ. Pol. 13, 140 (2018)

8. N. Zubarevich. J. of NEA, 2 (46), 162 (2020)

9. M. Pakhomov, I. Narizhny, $D$. Sechenov Soc.-econ. phenom. and proc. 10, 73-80 (2015)

10. E. Kiseleva, Fin.: th. and pr. 24(5), 80 (2020)

11. YU. Aksyutina, Mod. res. on soc. probl. 11-2, 16-25 (2016)

12. S. Belev., V. Veterinarov, O. Suchkova. HSE ECOn. J. 25(1), 30 (2021)

13. T. Tsatkhlanova, E. Erdnieva Bull. of the Uni. 16, 83-87 (2014).

14. Federal State Statistics Service. Retrieved from: https://rosstat.gov.ru/folder/10705

15. Map of clusters in Russia. Retrieved from: http://map.cluster.hse.ru/list

16. Open data portal of the Russian Federation. Retrieved from: https://data.gov.ru/

17. Ministry of Industry and Trade of Russia. GISIP. Industrial clusters. Retrieved from: https://gisp.gov.ru/gisip/\#!en/clusters/

18. SME Corporation. Retrieved from: https://corpmsp.ru/upload/19.10.2020 . pdf 